\title{
Survey of dairy housing and manure management practices in California
}

\author{
D. Meyer, ${ }^{\star 1}$ P. L. Price, ${ }^{\star}$ H. A. Rossow, $\dagger$ N. Silva-del-Rio,‡ B. M. Karle,§ P. H. Robinson, ${ }^{\star}$ E. J. DePeters, ${ }^{*}$ \\ and J. G. Fadel* \\ *Department of Animal Science, One Shields Avenue, University of California, Davis 95616-8521 \\ †Veterinary Medical Teaching Research Center, 18830 Road 112, Tulare, CA 93274 \\ łUniversity of California Cooperative Extension, 4437 South Laspina St., Ste. B, Tulare 93274 \\ §University of California Cooperative Extension, PO Box 697, Orland 95963
}

\section{ABSTRACT}

In 2007, a descriptive survey was mailed to all dairies in Glenn (G) and Tulare (T) Counties to identify current and future opportunities of manure management practices on California dairies. The purpose was to provide baseline information for development of outreach curriculum and a decision support tool to quantify potential benefits of various $\mathrm{N}$ management options on dairy farms. Such baseline information is valuable to staff regulating dairy facilities (e.g., San Joaquin Valley Unified Air Pollution Control District and Central Valley Regional Water Quality Control Board), dairy trade association representatives, and technology vendors. Response rates for each county were similar at $29.7 \%(\mathrm{n}=19 ; \mathrm{G})$ and $26.7 \%(\mathrm{n}=88$; $\mathrm{T}$ ). Mean milking herd size averaged 570 (range 50 to 3,000 ) cows in $\mathrm{G}$ and 1,800 (range 196 to 9,286 ) cows in T. Survey data are reported by location due to differences between counties in herd size, housing facilities, and climate. Freestalls are common housing facilities $(63.2 \%, \mathrm{G} ; 38.6 \%, \mathrm{~T})$ and separated solids and corral scrapings are commonly used as bedding in freestalls (81.8\% $\mathrm{G}$ and $79.4 \% \mathrm{~T})$. The most common methods of manure collection were flushing and scraping $(18.8 \%$, G; $44.7 \%, \mathrm{~T})$, only flushing $(43.8 \%$, G; $34.1 \%$, T), or only scraping daily or less frequently than daily $(37.5 \%$, $\mathrm{G} ; 20.0 \%, \mathrm{~T})$. Most dairy farms in $\mathrm{G}(63.2 \%)$ and $\mathrm{T}$ $(70.5 \%)$ used some method of separating solids from liquids. However, mechanical separation systems alone were used by $5.3 \% \mathrm{G}$ and $11.4 \% \mathrm{~T}$ of dairy farms. Storage or treatment ponds were found on $95.9 \%$ of dairies. Respondents identified existing manure management practices and did not indicate any new technologies were in use or being considered for manure management. Survey results were used to describe the 2 predominant manure management pathways of manure collection, storage, treatment, and utilization. Survey

Received August 26, 2010.

Accepted April 27, 2011.

${ }^{1}$ Corresponding author: dmeyer@ucdavis.edu results will be used to develop and disseminate targeted information on manure treatment technologies, and onfarm evaluation of implemented technologies related to anaerobic digesters, solid liquid separation, and pond additives.

Key Words: dairy manure management practices, mitigation measures, survey

\section{INTRODUCTION}

California Central Valley dairies produce more than $15 \%$ of the nation's milk and are subject to increasing regulatory requirements and rules to monitor and decrease their emissions of pollutants that may adversely affect the environment. Regulations in California often lead to changes in national policy and drive technology innovation on facilities throughout the nation. Manure management practices have an effect on air and water quality and, therefore, are the focus of multiple local and state regulatory and permitting agencies, with potentially conflicting needs. Although rules and regulations aimed at controlling manure management practices are already in place in California, current descriptive information as to methods and implementation of manure management practices used do not exist; hence, the need for this study.

The San Joaquin Valley Unified Air Pollution Control District (SJVUAPCD) recently imposed new regulatory requirements on dairies to decrease emissions of particulate matter (Rule 4550; SJVUAPCD, 2004) and volatile organic compounds (VOC; Rule 4570; SJVUAPCD, 2010). The contribution of $\mathrm{N}$ volatilization to development of particulate nitrate is also a concern to the SJVUAPCD. These new rules require that California dairy farms with estimated emissions exceeding one-half of major threshold emissions of oxides of $\mathrm{N}$ or VOC obtain a Permit to Operate (PTO). Areas within dairy operations requiring implementation of mitigation measures include feed and silage, milk parlor, freestall barn, corral, solid waste, liquid waste, and land application areas (Rule 4570; SJVUAPCD, 2010). Areas on individual dairy operations where manure is deposited, 
stored, treated or utilized are subject to permitting requirements. Facilities with a PTO must submit an application for Authority to Construct (ATC) to the SJVUAPCD before installing or modifying equipment or making changes to management that either causes or controls air emissions. Modifications to any or all permit units at a facility with a PTO require submission of an ATC. The SJVUAPCD staff review the ATC to determine if increased VOC emissions exceed the threshold from any one permit unit as a result of the proposed facility modification and, if so, identify necessary mitigation measures before approving the facility modification. Determination of achieved in practice is an important component to identify whether a practice or technology shall be included in SJVUAPCD permit requirements as a Best Available Retrofit Control Technology. Technology vendors should first verify emission(s) reductions to the SJVUAPCD before marketing to dairy operators. Adoption of technologies by operators absent SJVUAPCD approval is non-compliant and subject to fines in addition to the permitting process.

Additionally, the water regulatory process for owners and operators of most California dairy farms recently changed from a Conditional Waiver of Waste Discharge Requirements to formal Waste Discharge Requirements. All dairy farms in the Central Valley must comply with the General Order for Existing Milk Cow Dairies (GO) from the Central Valley Regional Water Quality Control Board (RB5; CVRWQCB, 2007) or Individual Waste Discharge Requirements (similar to the GO) developed specifically for each operation. To protect groundwater quality, the GO restricts the application of $\mathrm{N}$ for each crop within each field to not exceed 1.40 to 1.65 times the $\mathrm{N}$ removed. Greater attention to the quantity and form (organic versus plant available) of $\mathrm{N}$ applied is required to achieve production objectives while also meeting regulatory $\mathrm{N}$ application limits.

Based on the most recent detailed information on dairy manure management practices in the Central Valley (Morse Meyer et al., 1997), few technologic alternatives were used for manure management. That survey summarized practices in the Southern Central Valley. It did not include facilities in northern counties. Staff at both the SJVUAPCD and RB5 are actively seeking information as to the current practices on dairies to identify opportunities to mitigate environmental effect of dairy manure management practices. The restriction on limiting $\mathrm{N}$ application to land and the concern of ammonia contribution to fine particulate matter provides a unique opportunity to define manure pathways and establish a decision support tool that can be used to estimate changes in $\mathrm{N}$ fate (solid or liquid form) and form (organic versus plant available). Most $\mathrm{N}$ lost in animal housing and manure collection/treatment systems is from the more readily plant-available $\mathrm{N}$ pool (excreted ammonium and urea hydrolyzed to ammonium), thereby leaving a higher concentration of organic $\mathrm{N}$ in manure. The plant availability of the latter is less predictable, as $\mathrm{N}$ mineralization must occur before $\mathrm{N}$ is plant available. Crop consultants need to differentiate between the fraction of applied $\mathrm{N}$ in the plant-available $\mathrm{N}$ pool, and the rate of $\mathrm{N}$ mineralization of the organic $\mathrm{N}$ pool. Higher proportions of organic N (over 30\%) may result in decreased crop yields, thereby missing the target removal of $\mathrm{N}$ (Chang, et al., 2006). The focus on $\mathrm{N}$ application to each crop on each field will result in dairy farm operators making manure management changes designed to bring the facility into compliance with applicable regulations.

Since 1994, many changes have been made in the California dairy industry. The number of dairy farms has decreased, but the number of cattle per herd has increased. Based on USDA census data (USDA, 1997, 2007), the percent of California cows residing in herds of 500 or more milk cows rose from $80.9 \%$ in 1997 to $91.2 \%$ in 2007; and the number of herds with more than 500 cows rose from 1,001 to 1,103 , a $10 \%$ increase. A new reporting category used in the 2007 Census identified $37.0 \%$ of cows resided on dairies with 2,500 or more cows in California.

In an attempt to identify the technologies and techniques most likely to assist dairy operators in meeting regulatory requirements, the California Air Resources Board facilitated the San Joaquin Valley Dairy Manure Technology Feasibility Assessment Panel. This Panel, composed of representatives from government, dairy industry, academia, environmental and conservation groups, was created to evaluate technologies that have a potential to improve the management and treatment of dairy manure in the San Joaquin Valley. However, few submissions included sufficient scientific data to determine the environmental and economic performance of the technology. Many submissions included only testimonials or marketing claims. The final report is available at http://www.arb.ca.gov/ag/caf/dairypnl/ dairypanel.htm. A second, even less successful, attempt to evaluate manure treatment technologies occurred in 2007. Too few submissions and a similar lack of detailed technical information made reasonable evaluation of any of the technologies impossible, in the judgment of the Panel. However, this information is vital to operators considering adoption of new technologies because implementation can be costly and time-consuming.

During the public process associated with adoption of and amendments to Rule 4570 and the GO and discussions with technology vendors submitting information to the Manure Technology Review Panel, it became 
clear that no current data existed that described the type of manure management practices that were currently in use on California dairy operations, although anecdotal evidence suggested that several new manure management practices and technologies might be in relatively widespread use. Scientific data were needed by the industry and regulatory agencies to identify current practices, understand manure flow pathways through farms, and determine dairy operator interest in new technologies.

A descriptive survey of dairy farm manure management practices in northern (Glenn; G) and southern (Tulare; $\mathbf{T}$ ) counties of the Central Valley was conducted in 2007. The aim was to identify existing practices and better understand producer interests in emerging technologies for manure management to help develop educational materials for dairy farm operators and industry professionals to identify opportunities for implementing manure treatment technologies. Additionally, the survey results will be used to develop a decision support tool for dairy operators to predict $\mathrm{N}$ flows through their systems with different management practices or technologies. Information obtained in the survey is essential to adequately develop an inclusive decision support tool to allow dairy farm operators to evaluate potential modifications of $\mathrm{N}$ (i.e., quantity and form) before investing financial and other resources in management changes. Such a tool would be a valuable asset to dairy producers throughout the country to improve their on-farm $\mathrm{N}$ utilization and nutrient balance.

\section{MATERIALS AND METHODS}

Two counties ( $\mathrm{G}$ and $\mathrm{T}$ ) were selected to represent dairy farms in the Central Valley. The dairies in these 2 counties represent more than $25 \%$ of the dairies in the Central Valley and encompass the full range of facility types and management practices found in the state of California (based on information submitted to RB5). A complete list of producers $(\mathrm{n}=67, \mathrm{G} ; \mathrm{n}=330, \mathrm{~T})$ was obtained from the California Department of Food and Agriculture. Accepted methodology to obtain improved response rate for mailed questionnaires was used (Linsky, 1975). All producers in each county were mailed a pre-survey introductory letter indicating the purpose of the survey and the estimated amount of time required to complete it. The survey packet arrived 7 to $10 \mathrm{~d}$ later and included a survey booklet; a pre-addressed stamped envelope; and a reward (University of California at Davis pencil). The objective of the survey was to identify dairy housing and manure management practices used currently and of interest in the future to dairy farm operators. Finally, a reminder letter was sent to producers who did not respond to the initial survey packet within 2 wk.

The survey booklet contained 19 multiple choice and fill-in-the-blank questions, which were unbiased. When appropriate, the last selection was other, which allowed producers the opportunity to identify an answer if it was not previously listed. Questions were segregated into categories as follows: animal housing, bedding, collection, storage/treatment, and utilization. Booklets were identified by number to avoid unnecessary followup correspondence to remind individuals to return the survey. Responses within each survey were reviewed for logic and completeness. Additionally, the answer to housing type was checked by comparing aerial photographs of each facility with housing selections identified. Data for herd size and land available for manure application were obtained from information submitted to RB5.

\section{RESULTS AND DISCUSSION}

The economic climate of dairy farming in California was positive at the time of the survey (i.e., milk and feed prices were favorable to producers). However, changes in management practices required by recently adopted air rules and water quality regulation had frustrated producers. Response rates for each county were similar at $29.7(\mathrm{G})$ and $26.7 \%(\mathrm{~T})$. The error rate for each county at the $90 \%$ confidence level is $16(\mathrm{G})$ and $7.5 \%(\mathrm{~T})$, according to standard survey analysis practices (Custom Insight Inc., 2010). Given the limited variability of the information requested in the survey, these error rates are acceptable. Data are reported by location due to differences in herd size characteristics, responses to questions about common management practices, housing facilities, and climate in the 2 counties. Herd characteristics are shown in Table 1. The average rainfall (December through March) is 34.6 $\mathrm{cm}(\mathrm{G})$ and $18.0 \mathrm{~cm}(\mathrm{~T})$, according to the Western Regional Climate Center (2010) database. Freestalls are common housing facilities for lactating animals in both counties $(63.2 \%$, G; $38.6 \%, \mathrm{~T})$. The USDA APHIS (2009) survey, with information from 5 western states (CA, WA, ID, NM, and TX), indicated that $49.7 \%$ of dairies housed lactating cows in freestalls. The average herd size (range) for dairies with freestalls in G was 801 cows (225 to 3,000 cows) and in $\mathrm{T}$ was 2,117 cows (493 to 4,253 cows). The most common bedding material in freestalls was separated solids (obtained by gravity or mechanical separation) and corral scrapings, $81.8 \%$ $\mathrm{G}$ and $79.4 \%$ T. Other bedding materials identified by operators included almond shells, rice hulls, sand, straw, rubber mats, and pasture. Common bedding for 
Table 1. Survey data and results by county

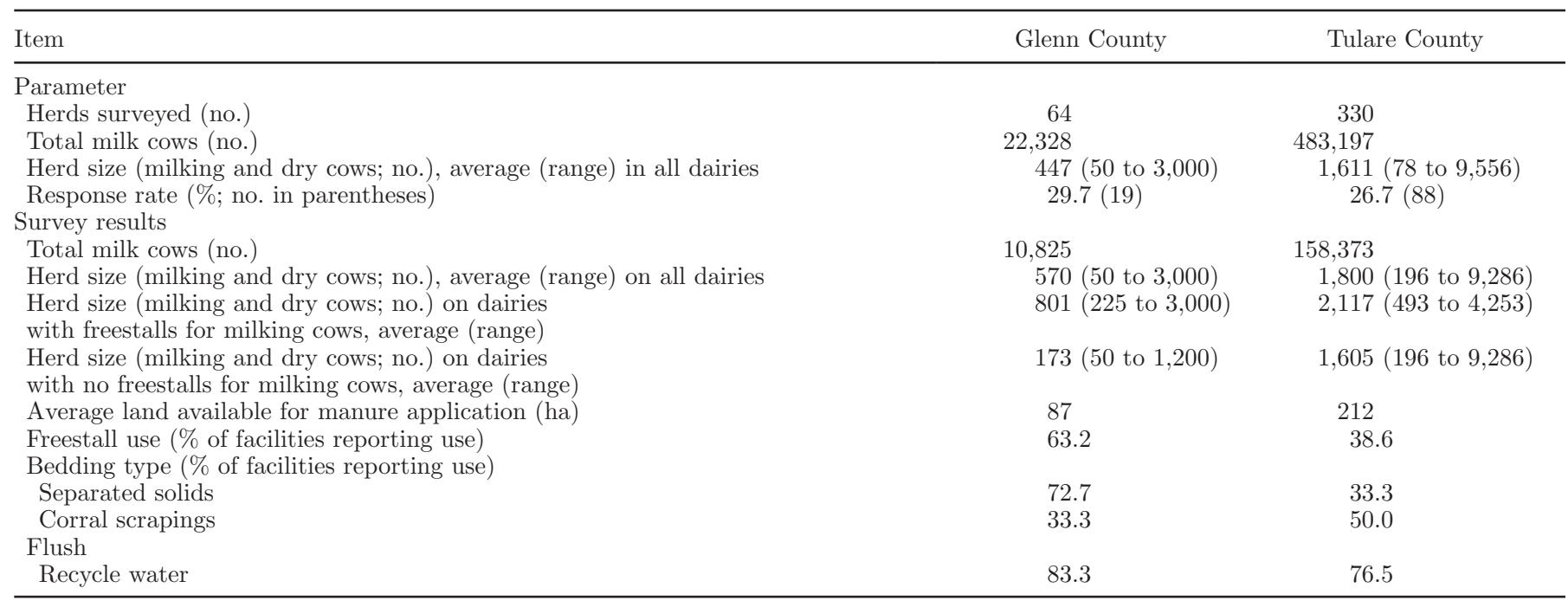

lactating cows on non-freestall dairies was corral scrapings $(65.8 \%, \mathrm{~T})$.

As expected, a variety of manure collection practices were used, depending on the physiological status of the animals. Both flushing and daily scraping were used to collect manure from housing areas where lactating cows resided $(18.8 \%, \mathrm{G} ; 44.7 \%, \mathrm{~T})$; only flushing $(43.8 \%$, G; $34.1 \%, \mathrm{~T})$; or only daily or less frequently than daily scraping $(37.5 \%, \mathrm{G} ; 20.0 \%$, T). Only one dairy farm (T) reported use of a vacuum system for manure collection. Although a specific question was not asked to address flushing frequency either in 1994 or 2007, it is likely that dairy farms with a PTO from the SJVUAPCD (Rule 4570 mitigation measures; SJVUAPCD, 2010) flush more frequently to remove manure from animal housing areas (applies only to T).

Recycled water from the liquid manure storage/treatment pond or rinse water from the milking parlor were used by $100 \%(\mathrm{G})$ where flushing was the method of manure collection. Similar water sources were used (T) to flush freestall lanes (90.5\%), fence line feed aprons in milk cow corrals $(92.3 \%)$, fence line feed aprons in heifer corrals (88.9\%), and flush alleys under calves $(78.6 \%)$. The balance of responses in each of these areas indicated freshwater as the source of water for flushing concrete lanes.

Although most dairy farms in $\mathrm{G}(63.2 \%)$ and $\mathrm{T}$ (70.5\%) used some method of separating solids from liquids, the percentage has increased since 1994, when only $54.1 \%$ of dairy farms reported separating solids from the liquid waste stream. Surprisingly, given the large footprint and expense of installation, gravity separation systems only (i.e., settling ponds or basins) were used on $42.1 \%(\mathrm{G})$ and $31.8 \%(\mathrm{~T})$ of dairy farms, up from $29.7 \%$ in the previous survey. Mechanical separation systems were used alone on $5.3 \%(\mathrm{G})$ and $11.4 \%(\mathrm{~T})$ of dairy farms compared with $9.5 \%$ in the previous survey. Anecdotal evidence had suggested that gravity separation systems were much more common than this, in spite of the fact that they provide little benefit other than providing a source of bedding material. A combination of gravity and mechanical separation methods was used on $15.8 \%(\mathrm{G})$ and $27.3 \%(\mathrm{~T})$ of dairy farms compared with $14.8 \%$ in the previous survey. No method of separating solids from liquids was reported on $36.8 \%(\mathrm{G})$ and $29.5 \%(\mathrm{~T})$ of dairy farms. On $\mathrm{T}$ dairy farms, where no solid-liquid separation occurred, manure from lactating cows was collected primarily through scraping $(69.2 \%)$, flushing $(19.2 \%)$, or a combination. The number of storage ponds reported by percent of dairy operators in $\mathrm{G}$ and $\mathrm{T}$, respectively, were $0,10.5$ and $4.5 \% ; 1,42.1$ and $39.8 \% ; 2,15.8$ and $36.4 \%$; $3,26.3$ and $13.6 \%$; and 4 or more, 5.3 and $5.7 \%$ (T). As expected, these numbers are similar to previous findings (Morse Meyer et al., 1997) where storage or treatment ponds were found on $95.9 \%$ of dairies. The percent of facilities with more than 1 cell in their storage or treatment pond system increased from $36.5 \%$ in 1994 (Morse Meyer et al., 1997) to $47.4 \%(\mathrm{G})$ and $55.7 \%(\mathrm{~T})$. Although expensive to install and maintain, additional cells in the liquid storage system may provide opportunities for more intensive management of the liquid stream. However, from a regulatory perspective, they increase surface area exposed to the atmosphere (potential for greater atmospheric emissions) and in contact with liquids (side walls and bottom of liquid storage structure), increasing the potential for nutrient infiltration to groundwater. 
Alleged treatment products (e.g., additives, aerators, sulfuric acid) to enhance biological decomposition of solids in liquid storage structures were reported on only $1 \mathrm{G}$ dairy farm. A total of $22.7 \%(\mathrm{n}=20)$ of dairies in $\mathrm{T}$ reported use of alleged pond treatment technologies: additives only (i.e., enzymatic, microbial, other; $10.2 \%)$, aerators only ( $5.7 \%)$, both additives and aerators $(5.7 \%)$, or sulfuric acid (1.1\%). Additionally, 5 dairy farms identified additions of clean water as a method to treat materials in liquid storage structures (i.e., dilution). The percent of dairy farm operators using pond additives alone justifies the development of an educational program to provide information to dairy producers to evaluate the effectiveness of these technologies in their production system. Future research should focus on studying the effectiveness of these treatments and identifying the fate and form of $\mathrm{N}$ when these are used.

Manure solids were piled and remained uncovered $(80.1 \%, \mathrm{G} ; 93.2 \%, \mathrm{~T})$ or were composted $(26.3 \%, \mathrm{G}$; $11.4 \%, \mathrm{~T})$. Only one dairy farm (T) reported anaerobic digestion as a solid treatment technology.

Predictably, both liquid and solid manures were often land applied. All dairies ( $\mathrm{G}$ and $\mathrm{T}$ ) applied liquid manure to land during the growing season. In a previous survey, $44.2 \%$ of dairy farms reported liquid manure application year round; however, our results indicated a decrease in this practice with only $26.3 \%(\mathrm{G})$ and $27.3 \%(\mathrm{~T})$. Slurry tanks were used at only a few dairy farms $(10.5 \%, \mathrm{G} ; 14.8 \%, \mathrm{~T})$ and no dairy farms reported using injection methods for land application of liquid/slurry manures. Generally, solid manure was used as bedding material $(47.4 \%, \mathrm{G} ; 55.6 \%, \mathrm{~T})$, spread on fields $(89.5 \%, \mathrm{G} ; 62.5 \%, \mathrm{~T})$, or manifested off-farm $(26.3 \%, \mathrm{G} ; 69.3 \%, \mathrm{~T})$.

Two predominant pathways of manure collection, storage, treatment, and utilization were evident in the responses received (Figure 1). Description of these pathways is the first step to develop a decision support tool to assist operators in understanding how changes in manure management practices may change form (solid or liquid) and composition (organic versus plant available). In 2004, the United States Environmental Protection Agency drafted a national ammonia emissions inventory (US EPA, 2004). Part of the document provided 8 flowcharts for manure movement through dairy operations. None of these pathways described by the Agency were representative of predominant pathways for manure movement through Central Valley California dairies. Five diagrams used waste storage tanks (not earthen impoundments). One diagram appeared to only address dairy heifers and dry cows. The two diagrams depicting fate of manure from lactating cattle neglected to include bedding contribution to $\mathrm{N}$ flow. The pathways identified through this survey differed from those provided in the draft emissions inventory.

The last area on the survey provided the dairy farm operators with an opportunity to identify potential future technologies of interest. It is worth noting that milk prices were favorable and feed prices were relatively stable when the survey was conducted, possibly providing a more accepting environment for new technologies. However, at that time, few alternative technologies were of interest to dairy farm operators, even though vendors of advanced treatment technologies were actively attempting to engage dairy farmers in technology deployment. Dairy farmers $(\mathrm{T})$ were interested in additional information on composting (4.5\%), solid-liquid separation (4.5\%), anaerobic digesters (12.5\%), and covering lagoons (4.5\%). In T, potential interest existed in additional information about carbon credits $(\mathrm{n}=$ 1) and commercial aerators $(n=1)$. In $\mathrm{G}$, additional information would be appreciated on compositing ( $\mathrm{n}$ $=1)$.

\section{CONCLUSIONS}

One key objective of this survey was to identify how manure was collected, stored, treated, and utilized to allow future development of a model, giving operators opportunities to explore how modification of manure management practices might modify $\mathrm{N}$ quantity and form. Although the average dairy herd size had increased since the previous survey in 1994, only one notable difference was found in manure collection, storage, or treatment between 1994 and 2007; that is, more farms reported use of solid-liquid separation systems. Use of gravity flow systems specifically increased at a higher rate than the increased use of mechanical separators. Few farmers reported use of alternative treatments, which are allegedly capable of enhancing OM decomposition. These findings are useful in defining expected manure management flows through dairy operations with standard housing setups. Results will be used to develop and disseminate targeted information on manure treatment technologies and on-farm evaluation of implemented technologies related to anaerobic digesters, solid-liquid separation, and pond additives.

\section{ACKNOWLEDGMENTS}

Research was supported in part by a UC ANR CORE Issues Grant 06-309, by W. K. Kellogg Endowment, and USDA NIFA Multistate Research Project S-1032. We gratefully acknowledge the participation by dairy operators in Glenn and Tulare Counties and infrastructure support of the Department of Animal Science, Col- 


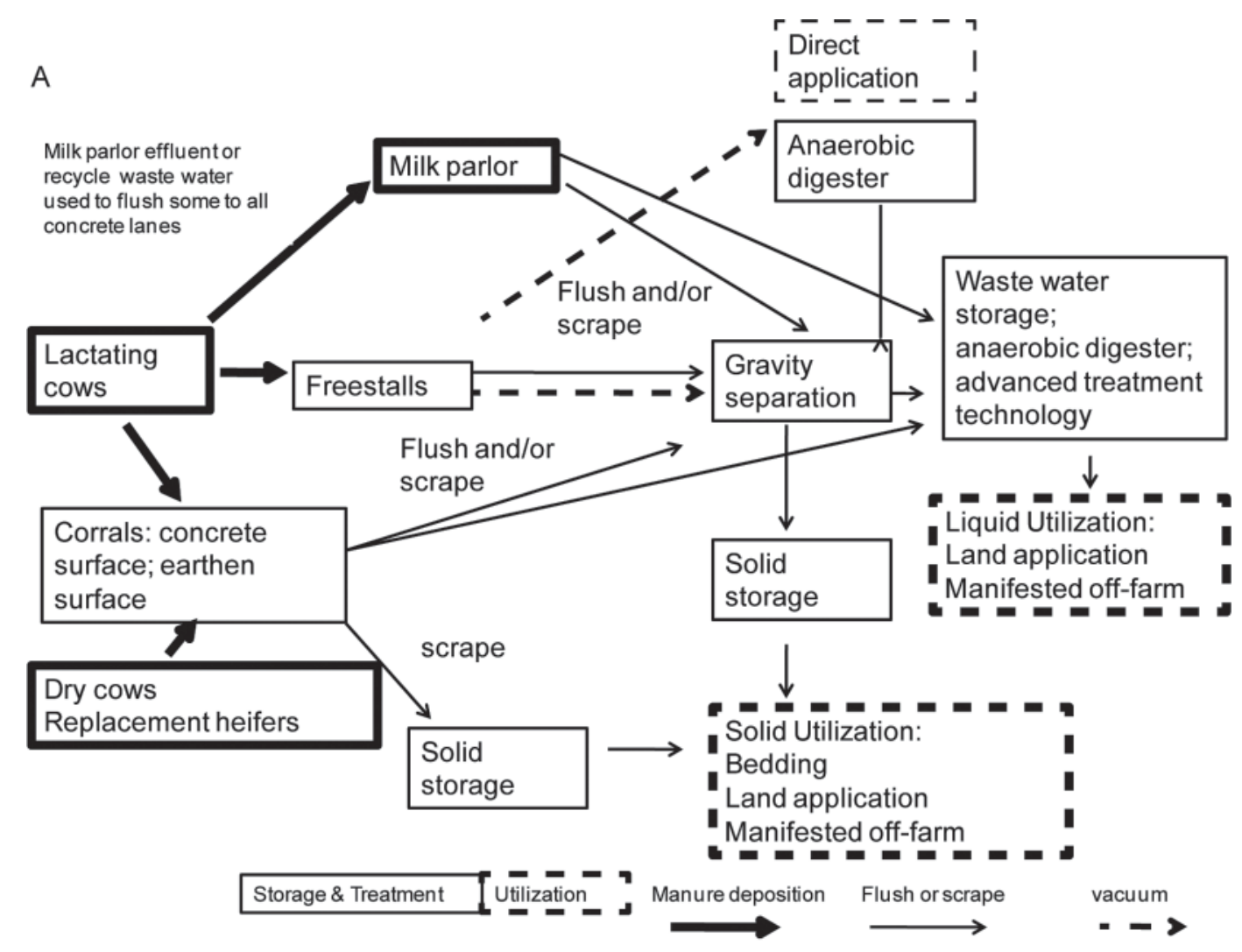

B

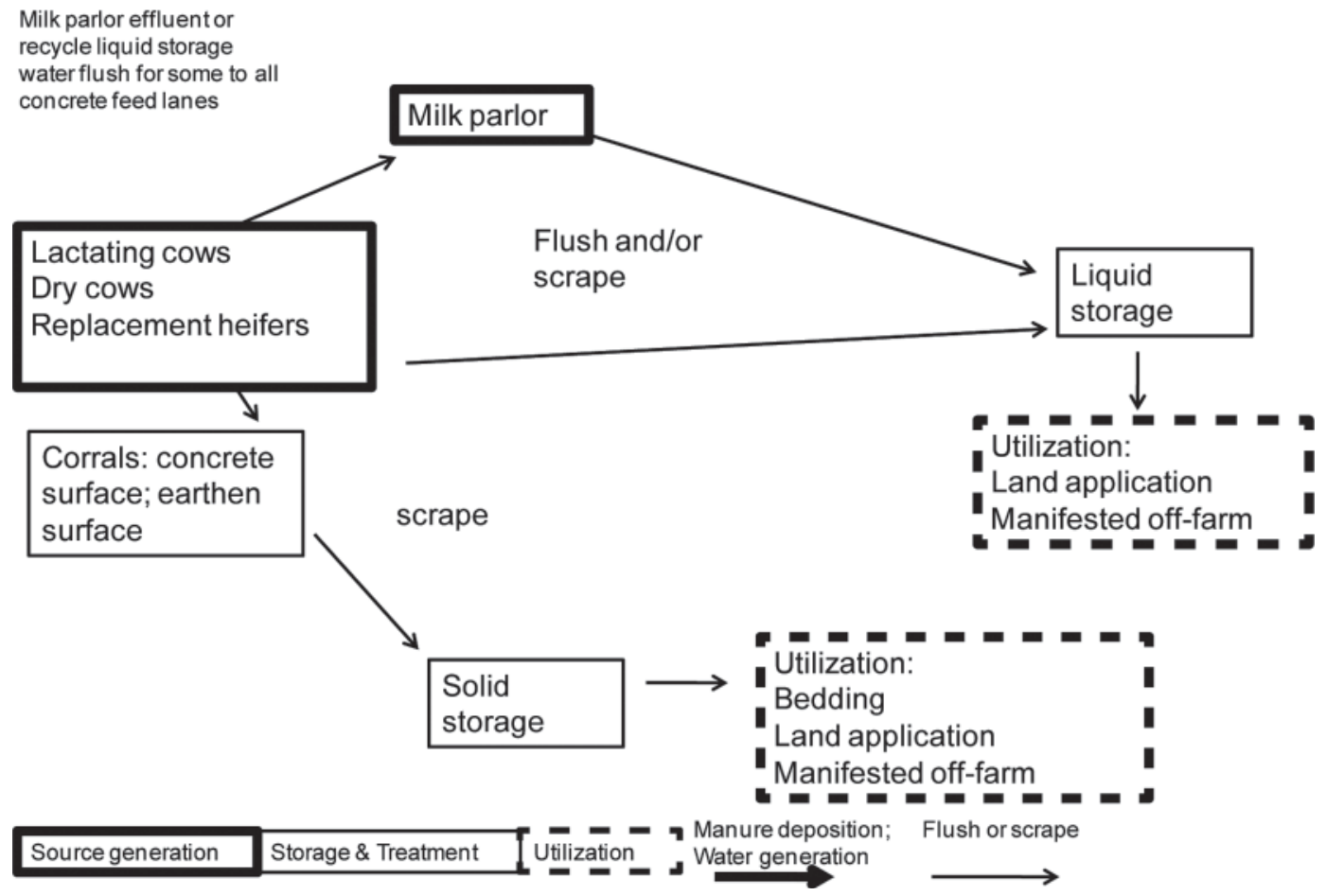

Figure 1. Predominant manure pathways where lactating cows are housed in Central Valley California dairies in freestalls (A) or without freestalls (B). 
lege of Agricultural and Environmental Sciences, and the California Agricultural Experiment Station of the University of California-Davis.

\section{REFERENCES}

Chang, A. C., T. Harter, J. Letey, D. Meyer, R. D. Meyer, M. Campbell-Mathews, F. Mitloehner, S. Pettygrove, P. Robinson, and R. Zhang. 2006. Groundwater Quality Protection: Managing Dairy Manure in the Central Valley of California. University of California, Agriculture and Natural Resources. Publication 9004. Accessed July 14, 2010. http://anrcatalog.ucdavis.edu/DairyCattle/9004.aspx.

Custom Insight Inc. 2010. Survey random sample calculator. Accessed Dec. 20, 2010. http://www.custominsight.com/articles/randomsample-calculator.asp.

CVRWQCB (Central Valley Regional Water Quality Control Board). 2007. General Order No. R5-2007-0035. Waste Discharge Requirements General Order for Existing Milk Cow Dairies. May 3, 2007. Accessed July 14, 2010. http://www.waterboards.ca.gov/centralvalley/board_decisions/adopted_orders/general_orders/r5-20070035.pdf.

Linsky, A. S. 1975. Stimulating responses to mailed questionnaires: A review. Public Opin. Q. 39:82-101.

Morse Meyer, D., I. Garnett, and J. C. Guthrie. 1997. A survey of dairy manure management practices in California. J. Dairy Sci. 80:1841-1845.

SJVUAPCD (San Joaquin Valley Unified Air Pollution Control District). 2004. Rule 4550: Conservation Management Practices. Ad- opted May 20, 2004. San Joaquin Valley Air Pollution Control District. Accessed July 14, 2010. http://www.valleyair.org/rules/ currntrules/r4550.pdf.

SJVUAPCD (San Joaquin Valley Unified Air Pollution Control District). 2010. Rule 4570: Confined Animal Facilities. Adopted June 15, 2006. Amended October 21, 2010. San Joaquin Valley Air Pollution Control District. Accessed Dec. 10, 2010. http://www.valleyair.org/rules/currntrules/R4570_1010.pdf.

USDA. 1997. Census of Agriculture - State Data. United States and Summary Data. Volume 1. Chapter 1. Accessed July 14, 2010. http://www.agcensus.usda.gov/Publications/1997/Vol_1_National,_State_and_County_Tables/California/ca-5/ca1_29.pdf.

USDA. 2007. Census of Agriculture. United States and Summary Data. Volume 1. Geographic Area Series. Part 51. AC-07-A-51. Accessed July 14, 2010. http://www.agcensus.usda.gov/Publications/2007/Full_Report/index.asp.

USDA APHIS (Animal and Plant Health Inspection Service). 2009. Dairy 2007: Part IV: Reference of dairy cattle health and management practices in the United States, 2007. Veterinary Services, National Animal health Monitoring System. Accessed Aug. 23 2010. http://www.aphis.usda.gov/animal_health/nahms/dairy/ downloads/dairy07/Dairy07_dr_PartIV.pdf.

US EPA (Environmental Protection Agency). 2004. National Emission Inventory-Ammonia emissions from animal husbandry operations. Draft report. Jan. 30, 2004. 131 pages. Accessed Dec. 20, 2010. http://www.epa.gov/ttnchie1/ap42/ch09/related/nh3inventorydraft_jan2004.pdf.

Western Regional Climate Center. 2010. Historical Climate Information Database. Accessed Dec. 21, 2010. http://www.wrcc.dri.edu. 